\title{
Regional Variation of Temperature and Rainfall in Bangladesh: Estimation of Trend
}

\author{
Abdur Rahman*, Md. Jibanul Haque Jiban, Sohul Ahmed Munna \\ Department of Statistics, Shahjalal University of Science and Technology, Kumargaon, Bangladesh \\ Email: ‘airdipu@student.sust.edu,jibanul@student.sust.edu, sohul.munna@yahoo.com
}

Received 5 July 2015; accepted 8 December 2015; published 11 December 2015

Copyright (C) 2015 by authors and Scientific Research Publishing Inc.

This work is licensed under the Creative Commons Attribution International License (CC BY). http://creativecommons.org/licenses/by/4.0/

(c) (7) Open Access

\section{Abstract}

This study mainly focuses on exploring the regional variation of the changing patterns of temperature and rainfall in Bangladesh. The analysis is based on the temperature and rainfall variation in Bangladesh over five regions as Dhaka, Cox's Bazar, Rajshahi, Bogra and Sylhet. The duration of the study period was chosen as 1953-2012 for Dhaka, 1948-2012 for Cox's Bazar, 1972-2012 for Rajshahi, 1958-2012 for Bogra and 1957-2012 for Sylhet. The findings of the non-parametric Mann-Kendal test reveal that significant increase of maximum temperature has been found in Cox's Bazar and Sylhet. Significant decrease of maximum temperature has been found in Dhaka and Bogra. Significant increase of minimum temperature has been found in Dhaka and Cox's Bazar whereas significant decrease has been found in Rajshahi. Significant decrease of rainfall has been found in Rajshahi among the study region. The maximum temperature increases significantly by 0.021 degree Celsius per year in Cox's Bazar and Sylhet. In case of minimum temperature highest increase is found in Dhaka by 0.049 degree Celsius followed by Cox's Bazar (0.038 degree Celsius per year) whereas significant decrease has been found in Rajshahi by 0.047 degree Celsius per year.

\section{Keywords}

Trend, Temperature, Rainfall, Regional Variation, Bangladesh

\section{Introduction}

Climate change is the long term change in average weather conditions whose main elements are temperature and rainfall. Since each and every being, particularly the human race, on the earth is the stake-holder of climate, and any change in the climate affects their stakes in one or another way.

"Corresponding author. 
The developing countries as well as underdeveloped world are the worst victims of climate change. As a developing country, Bangladesh is one of the most vulnerable countries in the world due to climate change.

Predictions of future climate of Bangladesh are available based on atmospheric and coupled atmosphericoceanic general circulation models and from regional climate models. Both the resolution and the accuracy of these models are improving; however, there are a number of uncertainties in predicted climates, especially in regional climates. There are large differences among inter-model forecasts. To overcome the uncertainties as well as to apprehend the magnitude and direction of future changes, it is necessary to evaluate the spatial and temporal changes that have already occurred in our past climate of Bangladesh. However, relatively few studies have been done in this respect though a vast body of literature is available on future climates from model predictions. Ahmed et al. (1992) [1] studied the trends in annual rainfalls of Bangladesh. They concluded that there was no significant trend in the annual rainfall over the country. Ahmad et al. (1996) [1] reported an increase of $0.5^{\circ} \mathrm{C}$ in temperature over Bangladesh during past 100 years. Rahman et al. (1997) [2] studied the long-term monsoonal rainfall pattern at 12 stations of Bangladesh. Though they found no overall trend in seasonal total rainfall, they detected some trends in monthly rainfalls of the two highly urbanized stations (Dhaka and Chittagong). Mondal and Wasimi (2004) [3] analyzed the temperatures and rainfalls of the Ganges Delta within Bangladesh and found an increasing trend of $0.5^{\circ} \mathrm{C}$ and $1.1^{\circ} \mathrm{C}$ per century in day-time maximum and night-time minimum temperatures, respectively. They also analyzed seasonal rainfalls of the delta. Though their results showed increasing trends in winter, pre-monsoon and summer rainfalls, there was no appreciable overall trend in critical period rainfall. Based on regional trends in temperatures and rainfalls, they concluded that the water scarcity in the dry season might increase and the critical period could become more critical in future. SAARC Meteorological Research Centre (SMRC, 2003) [4] studied surface climatological data on monthly and annual mean maximum and minimum temperatures, and monthly and annual rainfalls for the period of 1961-1990. The study showed an increasing trend of mean maximum and minimum temperatures in some seasons and decreasing trend in some others. Overall, the trend of the annual mean maximum temperature had shown a significant increase over the period of 1961-1990. Rahman and Alam (2003) [5] found that the temperature was generally increasing in the June-August period. Average maximum and minimum temperatures showed an increasing trend of $5^{\circ} \mathrm{C}$ and $3^{\circ} \mathrm{C}$ per century, respectively. On the other hand, average maximum and minimum temperatures of December-February period showed, respectively, a decreasing and an increasing trend of $0.1^{\circ} \mathrm{C}$ and $1.6^{\circ} \mathrm{C}$ per century. Regional variations had also been observed around the average trend (SMRC, 2003) [4]. In a recent study, Climate Change Cell (2009) [6] had analyzed the temperature and sunshine duration at all BMD stations of Bangladesh. It had also analyzed rainfall trend at eight stations. Rainfall data at other stations could not be analyzed due to time and budgetary limitations and also, the rainfall data after the year of 2001 were not available for the study. Islam and Neelim (2010) [7] analyzed the maximum and minimum temperatures of four months (January, April, May and December) and two seasons only. The two months of April-May were considered as the summer season and the two months of December-January as the winter season in the study. The study found in general an increasing trend in both summer and winter temperatures. The rainfall data of some selected locations were also studied by Islam and Neelim (2010) [7]. However, they did not make any complete assessment of trend in rainfall in different time scales. Most of their analyses were on simple distribution of rainfall in a form of bar graphs.

\section{Methodology}

Assessing the changing patterns of climate is a vast issue since enormous factors and elements are directly or indirectly responsible for the changing of a climate system, locally and globally. Most common instruments used to observe and measure the climate are:

- Temperature

- Rainfall

- Snow, glacial and permafrost melt

- Greenhouse gas levels

- Sea level

- Extreme weather events

The study deals with temperature and rainfall over five weather station of BMD from five different region of 
Bangladesh defined by Cox’s Bazar (South-Eastern zone), Sylhet (North-Eastern zone), Bogra (North-Western zone), Rajshahi (Western zone) and Dhaka (South-Central zone).

The reasons behind selecting these stations are availability of the long time data, minimum missing observations and covering almost all topological region of Bangladesh.

\subsection{Data}

The necessary data for this study has been collected from Bangladesh Meteorological Department (BMD) which is the authorized government organization for meteorological activities of Bangladesh.

The duration of the study period was chosen as 1953-2012 for Dhaka, 1948-2012 for Cox’s Bazar, 1972-2012 for Rajshahi, 1958-2012 for Bogra, and 1957-2012 for Sylhet.

\subsection{Theory}

Temporal trend is the gradual change in a variable at a specific location with time. Such change can be linear or non-linear, and monotonic or non-monotonic. Linear monotonic change is expressed in the following form:

$$
Y=a+b t+\varepsilon
$$

where, $Y$ is the dependent variable such as temperature, rainfall, sunshine duration or humidity;tis the independent variable which is time (year) in this case; $\varepsilon$ is the random variation (noise) in the dependent variable; $a$ and $b$ are, respectively, the intercept and slope of the linear trend line. The estimate of $b$ is the change in the variable per unit time, and is the linear trend. The two parameters ( $a$ and $b$ ) can be estimated by the parametric or non-parametric method. Parametric method is commonly used and is robust in case of normally distributed residuals (noise) and in absence of outliers and extremes in the data set. Otherwise, a non-parametric method becomes more suitable. In parametric method, the parameters are estimated by an ordinary least-squares regression (OLS) technique. It is required in such estimation that the residuals be normally, independently and identically distributed. It is to be noted that the above requirements are for the residuals, and no assumptions are made concerning the distribution of either the explanatory or the response variable.

For testing the statistical significance of trend, the most commonly used statistic in parametric method is Pearson's $r$. Pearson's $r$ measures the linear monotonic association between two variables and most widely used. Kendall's $\tau$ and Spearman's $\rho$ are usually used to measure both linear and non-linear monotonic associations between two variables. Both $\tau$ and $\rho$ are rank-based procedures-the latter being dependent on the actual magnitudes of the two variables, while the former being not dependent on them. The values of these three correlation coefficients indicate the presence or absence of the trend and its direction (increasing or decreasing). However, the coefficient in itself does not indicate whether the trend is statistically significant or not at a given confidence level. For that purpose, a $t$-test for Pearson's $r$ and a $z$-test for Kendall's $\tau$ can be used (Helsel and Hirsch, 2002) [8]. Bhattacharyya and Johnson (1977) [9] present the exact and large sample approximation versions of the significance testing for Spearman's $\rho$. By this way, onecan know whether there is any significant increasing or decreasing trend in a data set.

In this study we analyze trend for maximum temperature, minimum temperature, mean temperature and rainfall data by Non-parametric Mann-Kendall (M-K) test using the Statistical Package for Social Sciences (SPSS) software.

\section{Result and Discussion}

The findings of the non-parametric Mann-Kendal test (Table 1) revealed that significant increase of maximum temperature has been found in Cox's Bazar and Sylhet, significant decrease of maximum temperature has been found in Dhaka and Bogra. Significant increase of minimum temperature has been found in Dhaka and Cox's Bazar whereas significant decrease has been found in Rajshahi. Significant decrease of rainfall has been found in Rajshahi among the study region (Figures 1-5).

The linear trend analysis (Figure 2, Figure 5, Table 2) revealed that the maximum temperature increased significantly by 0.021 degree Celsius per year in Cox's Bazar and Sylhet.

In case of minimum temperature highest increase was found in Dhaka by 0.049 degree Celsius followed by Cox's Bazar (0.038 degree Celsius per year) whereas significant decrease has been found in Rajshahi by 0.047 degree Celsius per year (Figures 1-3). 
Table 1. Mann-Kendall's test statistics in selected regions of Bangladesh.

\begin{tabular}{|c|c|c|c|c|c|}
\hline Variables (Monthly) & Stations & Scores (S) & Kendall's $\tau$ & P-value & Trend \\
\hline \multirow{5}{*}{ Maximum Temperature } & Dhaka & -334 & -0.191 & 0.033 & Decreasing \\
\hline & Rajshahi & -80 & -0.098 & 0.376 & No significant trend \\
\hline & Cox’s Bazaar & 533 & 0.260 & 0.002 & Increasing \\
\hline & Bogra & -416 & -0.262 & 0.004 & Decreasing \\
\hline & Sylhet & 539 & 0.344 & 0.001 & Increasing \\
\hline \multirow{5}{*}{ Minimum Temperature } & Dhaka & 737 & 0.423 & 0.000 & Increasing \\
\hline & Rajshahi & -309 & -0.382 & 0.000 & Decreasing \\
\hline & Cox’s Bazaar & 897 & 0.440 & 0.001 & Increasing \\
\hline & Bogra & 70 & 0.044 & 0.634 & No significant trend \\
\hline & Sylhet & 222 & 0.141 & 0.128 & No significant trend \\
\hline \multirow{5}{*}{ Average Temperature } & Dhaka & 225 & 0.128 & 0.152 & No significant trend \\
\hline & Rajshahi & -72 & -0.137 & 0.270 & No significant trend \\
\hline & Cox’s Bazaar & 898 & 0.435 & 0.000 & Increasing \\
\hline & Bogra & -370 & -0.233 & 0.011 & Decreasing \\
\hline & Sylhet & 391 & 0.247 & 0.007 & Increasing \\
\hline \multirow{5}{*}{ Rainfall } & Dhaka & 44 & 0.024 & 0.783 & No significant trend \\
\hline & Rajshahi & -106 & -0.201 & 0.091 & Decreasing \\
\hline & Cox’s Bazaar & 102 & 0.049 & 0.567 & No significant trend \\
\hline & Bogra & 62 & 0.038 & 0.674 & No significant trend \\
\hline & Sylhet & 136 & 0.085 & 0.352 & No significant trend \\
\hline
\end{tabular}

Table 2. Linear trends for annual maximum and minimum temperature in selected regions of Bangladesh.

\begin{tabular}{ccccc}
\hline \multirow{2}{*}{ Weather Stations } & \multicolumn{2}{c}{ Yearly Maximum Temperature } & \multicolumn{2}{c}{ Yearly Minimum Temperature } \\
\cline { 2 - 5 } & $\%$ of Fluctuations Rate $\left({ }^{\circ} \mathrm{C}\right)$ & Climate Line $\left({ }^{\circ} \mathrm{C}\right)$ & \% of Fluctuations Rate $\left({ }^{\circ} \mathrm{C}\right)$ & Climate Line $\left({ }^{\circ} \mathrm{C}\right)$ \\
\hline Dhaka & $-2.5^{\mathrm{a}}$ & 38.88 & $4.9^{\mathrm{a}}$ & 7.14 \\
Cox's Bazaar & $2.1^{\mathrm{a}}$ & 34.83 & $3.8^{\mathrm{a}}$ & 10.82 \\
Sylhet & $2.1^{\mathrm{a}}$ & 35.95 & 1.6 & 8.57 \\
Rajshahi & -0.4 & 41.27 & $-4.8^{\mathrm{a}}$ & 8.24 \\
Bogra & $-5.7^{\mathrm{a}}$ & 41.35 & 0.6 & 7.57 \\
\hline
\end{tabular}

${ }^{\mathrm{a}}$ Significant at $5 \%$ level.

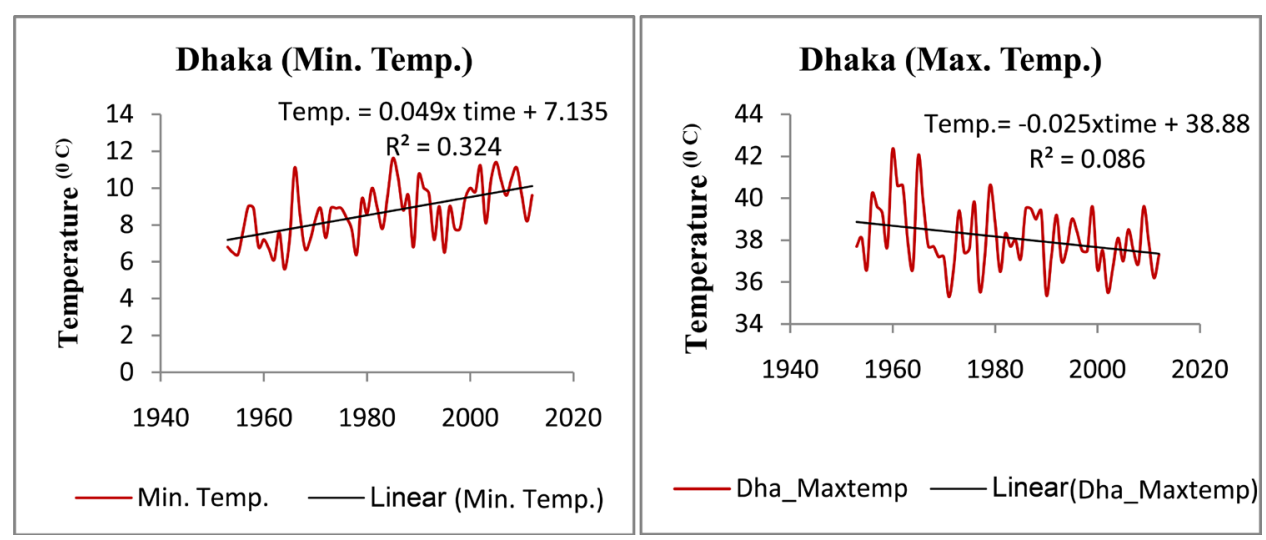

Figure 1. Linear trend for yearly minimum and maximum temperature (Dhaka). 


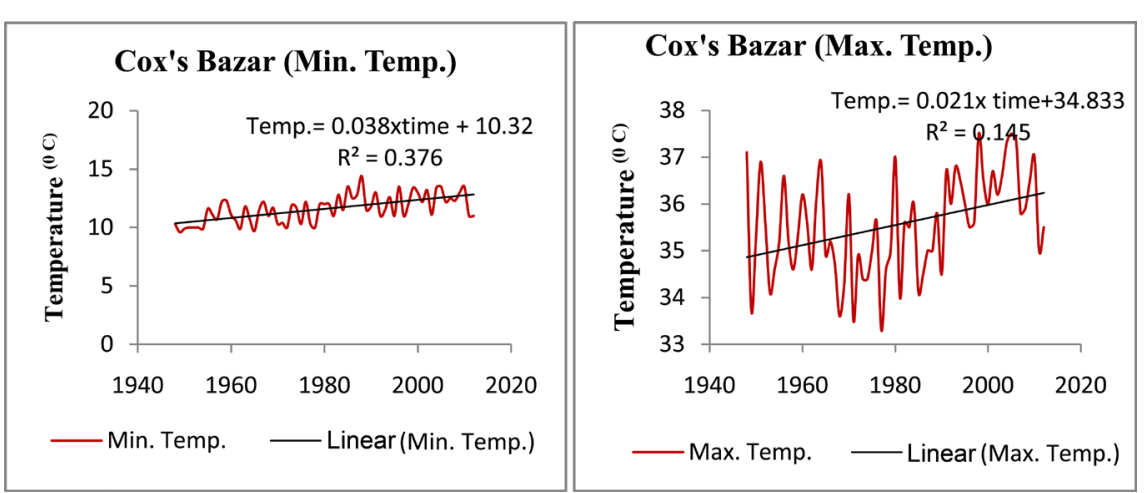

Figure 2. Linear trend for yearly minimum and maximum temperature (Cox’s Bazar).

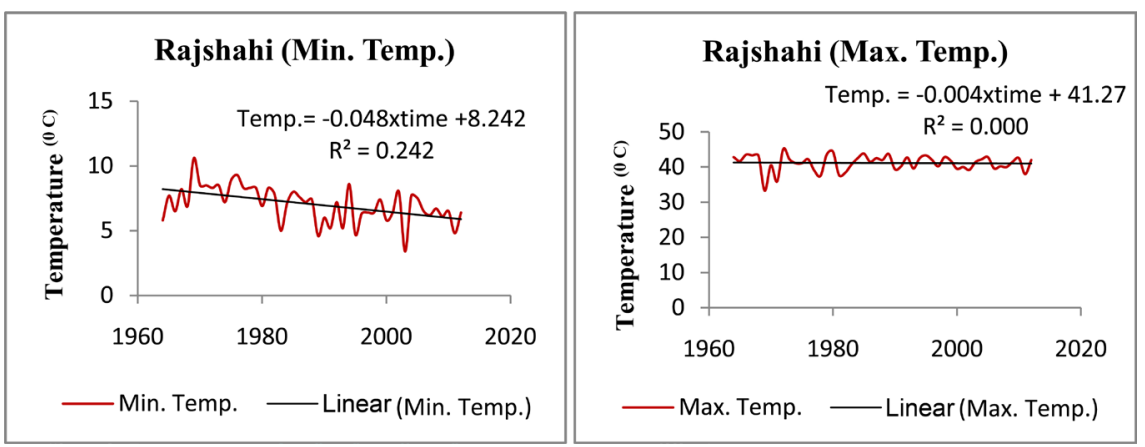

Figure 3. Linear trend for yearly minimum and maximum temperature (Rajshahi).

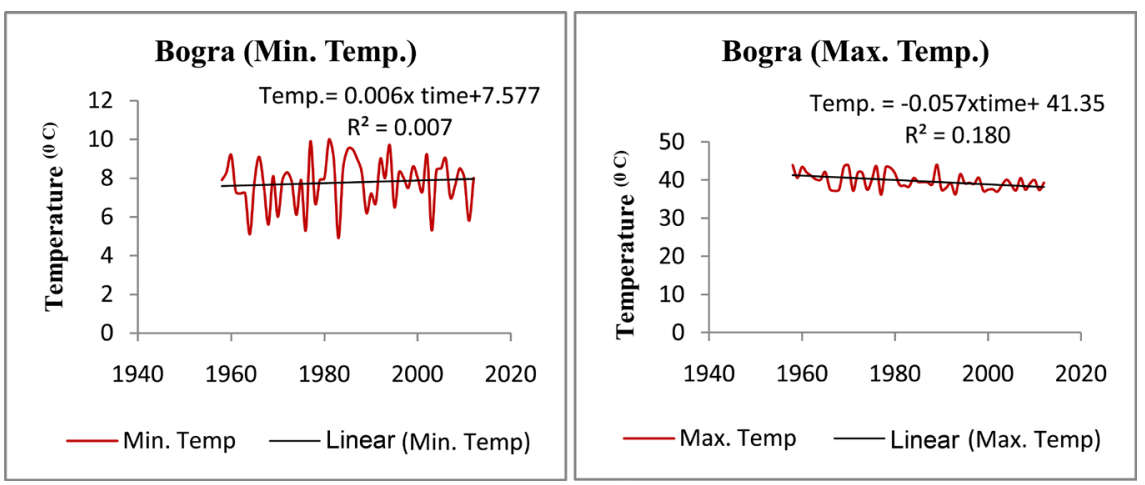

Figure 4. Linear trend for yearly minimum and maximum temperature (Bogra).
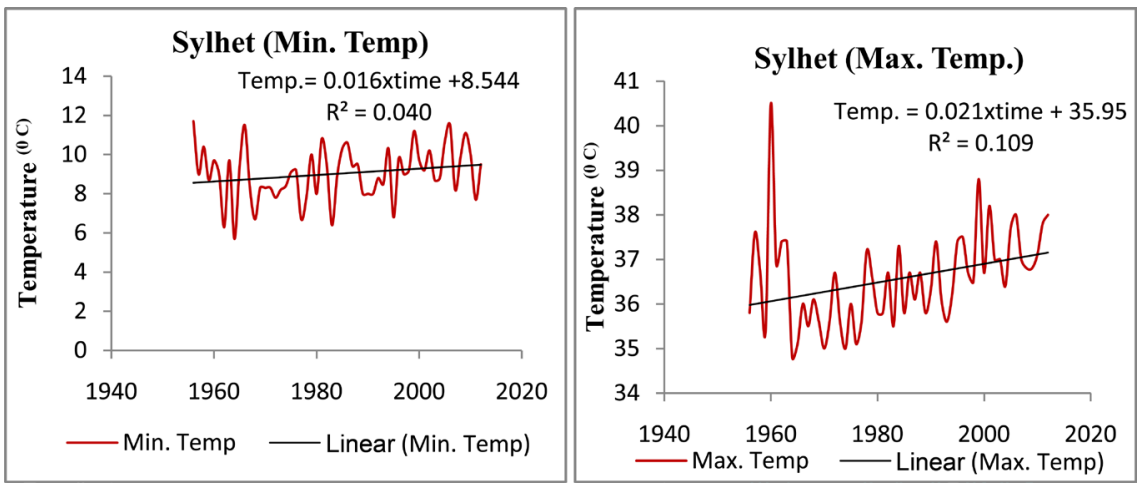

Figure 5. Linear trend for yearly minimum and maximum temperature (Sylhet). 


\section{Conclusion}

Though climate change in Bangladesh in terms of temperature and rainfall has incepted since long, this climate change has got tremendous momentum since the advent of 90's. Because of the adverse impact of this climate change, the Rajshahi region in Bangladesh has become the most vulnerable region and this process still continues at an increasing rate. Besides, the vulnerability of Cox's Bazar as well as Sylhet region to climate change has become very mush alarming. The policy implications derived from the findings of the study lie in that Bangladesh is a very vulnerable country to climate change in terms of temperature and rainfall and minimize the adverse effect of climate change on the life and livelihood of the inhabitants of Bangladesh. Cautionary and appropriately adaptive measures should be tailored and exercised. Dialogues at both national and international levels should be launched in different forums to ameliorate the adverse factors of climate change. Since this field has still under-researched in Bangladesh, further comprehensive and appropriate research can be undertaken and implemented in this very field to produce more authentic findings for policy implications.

\section{Acknowledgements}

We thank the Bangladesh Meteorological Department (BMD) for providing the data which is the authorized government organization for meteorological activities of Bangladesh. Especially thanks to Md. Mahedi Hasan (Lecturer, Bangladesh University of Professional) for giving inspiration.

\section{References}

[1] Ahmed, S.M.U., Hoque, M.M. and Hussain, S. (1992) Floods in Bangladesh: Ahydrological Analysis. Final Report No. R01/92, IWFM, BUET, Kumargaon.

[2] Rahman, M.R., Salehin, M. and Matsumoto, J. (1997) Trend of Monsoon Rainfall Pattern in Bangladesh. Bangladesh Journal of Water Resources Research, 14-18, 121-138.

[3] Mondal, M.S. and Wasimi, S.A. (2004) Impact of Climate Change on Dry Season Water Demand in the Ganges Delta of Bangladesh. In: Rahman, M.M., Alam, M.J.B., Ali, M.A., Ali, M. and Vairavamoorthy, K., Eds., Contemporary Environmental Challenges, CERM, ITN, BUET, WEDC, IDE and Loughborough University, UK, 63-83.

[4] SMRC (2003) The Vulnerability Assessment of the SAARC Coastal Region Due to Sea Level Rise: Bangladesh Case. SAARC Meteorological Research Centre, Dhaka.

[5] Rahman, A. and Alam, M. (2003) Mainstreaming Adaptation to Climate Change in Least Developed Countries (LDCs). Working Paper 2: Bangladesh Country Case Study, IIED, London.

[6] Climate Change Cell (2009) Characterizing Long-Term Changes of Bangladesh Climate in Context of Agriculture and Irrigation. Department of Environment, Dhaka.

[7] Islam, T. and Neelim, A. (2010) Climate Change in Bangladesh: A Closer Look into Temperature and Rainfall Data. The University Press Limited, Dhaka.

[8] Helsel, D.R. and Hirsch, R.M. (2002) Statistical Methods in Water Resources. U.S. Geological Survey.

[9] Bhattacharyya, G.K. and Johnson, R.A. (1977) Statistical Concepts and Methods. John Wiley, New York. 